\title{
Features of career self-determination of regional university applicants in the context of the COVID-19 pandemic
}

\author{
Faina Kremen*, and Sergei Kremen \\ Smolensk State University, Przhevalsky str., 4, 214000 Smolensk, Russia
}

\begin{abstract}
The impact of the COVID-19 pandemic on the career plans of high school graduates in 2020 is examined in article. At the stage of graduating from high school and admission to university, career selfdetermination is considered in the context of professional selfdetermination, an indicator of the development of which is a conscious choice of a professional future. As a result of a survey and diagnostic of 127 first-year students of Smolensk State University, it was found that students who entered the university with formed professional plans have a higher level of development of personal competencies that are significant for career self-determination. Most of them implemented their university admission plans despite the limitations associated with the COVID-19 pandemics. At the same time, students who did not have formed career ideas at the time of admission experienced more difficulties in entering; their choice of the training program was due to external factors.
\end{abstract}

\section{Introduction}

At the present time, the concept of "career", being the subject of study in many fields of social knowledge, significantly expands its meaning, taking into account the changing realities of the world of professions in post-industrial society. Even before the outbreak of the pandemic, there was a well-established idea of the mobility of career plans [1-2], according to which people cannot stay in a single job throughout their lives, their workplace will change many times. The idea of a career as a professional and status advancement on the career ladder is replaced by an expanded understanding of it as a "lifelong learning process, within which an individual regulates his training and professional activities to create a quality life" [3, p. 9]. As part of this process, an individual can repeatedly change the direction of activity, combine professional tracks or work simultaneously in several professional fields, and career is increasingly viewed in conjunction with the concept of personal success, and not only with social recognition and prestige [4]. Kovalevskaya [5] considers career self-determination as a psychoreflexive activity aimed at finding one's own way of building a career and creating its image, which includes key personal formations.

Despite the fact that the career context goes beyond the labor activity, including nonprofessional aspects of being a person, profession and work are the most important

*Corresponding author: fmkremen@gmail.com 
condition for career advancement. We believe that the system-forming component of career development is professional self-determination, which reveals the process of the formation and development of a person as a subject of labor activity.

The researchers associate the initial stage of career development with the psychological processes of personal and professional self-determination during school education. Much attention is paid to specially organized activities aimed at supporting self-determination professional orientation in foreign and domestic science [6].

Moskalenko [7] notes that career guidance connects the choice of a profession with the life goals of an individual and its ultimate goal is not one-time assistance in professional educational choice, but the preparation of the student for independent and conscious socioprofessional self-determination [8], including information necessary for planning their future career [9]. At the same time, a number of studies note [10-11] that often parents, in comparison with teachers or professional counselors, continue to be one of the most frequently used and influential sources of information and advice about careers, especially in traditional cultures [12].

An important task of career planning is the development of professional motivation. Sakhovsky [13] emphasizes that the school career planning period should be focused on the formation of professional orientation and readiness of students to implement a personal professional plan in the future.

Studies [14-16] show a strong relationship between the presence of future orientations in young people and greater variability in career scenarios, conscious goals and plans, and high motivation to achieve them. Also, future orientation is positively associated with measurable indicators of school and career achievements and plays an important role in the formation of personal qualities associated with career search skills and commitment to their professional interests [15].

According to Russian researchers [17], the prevailing motives for students choosing a certain educational specialization indicate that a significant part of them (40\%) consciously make this choice: they know their own capabilities and want to get an interesting and varied job after graduation. External factors of prestige and monetary motives were significant for $20 \%$ of the respondents. However, there are still students $(6 \%)$ whose choice of profession is random. The study also shows that $52 \%$ of the respondents are going to work in their specialty, while $38 \%$ have not yet decided, and a tenth part of the respondents do not plan to work in their specialty. These results indicate the difficulties of the process of career selfdetermination, the unpreparedness of some young people for this activity.

Difficulties in making career decisions are one of the factors, the study of which is necessary to understand the causes and mechanisms of career development of the individual [18]. The theoretical understanding of the reasons for the difficulties associated with making career decisions gives rise to disputes over how serious an impact unpredictable and unplanned events can have on career choices, and how much the individual remains the subject of such choices. Thus, approaches based on the theory of constructivism claim that since people themselves create their own meaning through personal life experience, career decisions and choices are highly subjective, that is, determined by the person himself, and not by external influences. On the other hand, systems theory considers the individual as part of a broader social context, and chaos theory, which develops this concept, recognizes that disorder, unpredictability, and lack of control are part of the normal career development process [19].

In this regard, it is important to determine whether the new reality caused by the COVID-19 pandemic affects the change in the professional and career plans of young people. Numerous studies conducted so far in Russia and abroad address various aspects of the impact of the COVID-19 pandemic on the education sector. At the same time, they focus on the readiness of schools and universities to switch to remote education and, 
accordingly, the deterioration of its quality [20], the interaction of teachers and students, schools and families [21], the problem of inequality of educational opportunities in the implementation of remote learning, due to the financial situation of families [22], the increase in the burden on students and teachers [23] and others. However, there is very little research (e.g. [24]) on how the economic, social, and psychological consequences of the pandemic affected the career choices of 2020 graduates.

Obviously, due to the short time frame, it is impossible to make generalizing conclusions, but large amounts of data allow researchers to make forecasts of possible scenarios, including the impact of objective circumstances on the motivation and behavior of high school and university students. In particular, it was found that the deterioration of the economic situation of families, fears associated with the spread of the disease, as well as the perception of electronic learning formats as less valuable, increases the cost and risks of moving to another city [25], which can lead to a decrease in the social mobility of applicants from small cities and remote territories, and, as a result, to a decrease in the demand of the population for higher education. Researchers suggest that educational and career trajectories will change in favor of early employment and preference for secondary vocational education organizations instead of universities [26]. However, the implementation of such a scenario is not obvious, since many states, in turn; take measures to increase the mobility of students, and studies confirming a real significant decrease in educational mobility are still insufficient [27].

\section{Materials and Methods}

\subsection{Purpose}

The purpose of the study was to determine whether the COVID-19 pandemic had a significant impact on the career self-determination of school graduates who entered a regional university.

Research questions:

- what motives determined the choice of the university and the possibility of admission, external, due to the restrictions caused by the COVID-19 pandemic, or internal, based on previously formed professional plans?

- are there any differences among graduates with different motivations in the level of development of personal characteristics that are important for career self-determination?

\subsection{Research methods}

We have developed a questionnaire aimed at identifying the characteristics of respondents ' self-determination, as well as problems of school graduation and university admission in the context of the COVID-19 pandemic. The first section of the questionnaire allowed us to collect information about the availability of professional plans of the respondents, the factors that influenced their formation, and the motivation for admission to the current training program. A separate section of the questionnaire contained questions about the impact of the pandemic and the conditions of remote learning on school performance, preparation for the Unified State Exam and their results, and, accordingly, on changes in career plans.

In addition, we used test for diagnosing personal competencies that are important for career self-determination, developed by Kovalevskaya [5]. The choice of the method is due to the fact that personal competencies are a condition for the success of professional and career self-determination, their development contributes to a conscious and responsible 
activity to create an image of a future career and find ways to build it. The method allows us to identify 8 groups of knowledge, skills, and experience related to various aspects of personal and career development: 1) awareness in the field of professional selfdetermination (APS), 2) awareness of the peculiarities of one's own personality (AP), 3) skills of cognitive reflection and self-control (SRS), 4) socially significant skills (SSS), 5) skills to harmonize personal and public interests (SHI), 6) planning skills (PS), 7) experience in solving personally and professionally significant tasks (EPPT) and 8) experience in solving socially significant tasks (EST). The results obtained are then integrated into four competencies of career self-determination (secondary factors): the ability and readiness to integrate personal and social interests in professional activity $(\mathrm{C} 1)$, the ability and readiness for professional interaction, and the solution of socially significant tasks $(\mathrm{C} 2)$, the ability and readiness for cognitive reflection $(\mathrm{C} 3)$, the ability and readiness to plan their career and professional future (C4).

\subsection{Participants}

The study involved first-year undergraduate students of Smolensk State University $(\mathrm{N}=127)$ who were applicants in the context of the COVID-19 pandemic in 2020.

\section{Results and discussion}

According to the results of the questionnaire, the test subjects were divided into two groups: the first group included those students whose admission was the result of a conscious choice (75 students $-59.1 \%$ ), the second group included students who entered under the influence of external factors (52 students - 40.9\%). Accordingly, the results of the study are presented in the form of a comparative analysis of these groups (hereinafter referred to as "G1" and "G2").

The respondents of G1 noted that their professional plans related to the current place of study were formed either in childhood $(22.7 \%)$, including under the influence of relatives, or in high school (77.3\%) when they thought about their future. The respondents of G2 chose their field of study only during the admission period, taking into account the USE scores and other circumstances.

Such socio-demographic characteristics as the place of residence and the financial situation of the family do not affect the external or internal motivation for admission (Table 1). Small differences are observed by gender, which may explain the additional external motivation for entering the University for Males as a more attractive alternative to military service. The significant differences between the groups according to the criterion of "program of training" can be explained by the fact that the teaching profession is more often chosen consciously, as it is more familiar and understandable to school graduates, that is, personal experience and the opinion of relatives continue to be a significant factor in the professional choice.

An analysis of the answers of the first-year students showed that studying in a specialized class is not a significant factor in a conscious professional choice. Thus, the share of students in the socio-economic and humanitarian profile was $37.3 \%$ among the respondents in G1 and 50\% among G2. In contrast, 50.7\% (G1) students studied in the class of a non-specialized profile, compared with $36.5 \%(\mathrm{G} 2)$.

Among the professional orientation activities held at school, respondents of both groups more often noted psychological testing (58.7\% and 53.4\%), meetings with representatives of Higher education and Vocational education organizations $(49.3 \%$ and $50 \%)$. The respondents also called the presence of a special subject "Career guidance" $(22.7 \%$ and $15.4 \%)$, conversations about choosing a profession with psychologists/teachers $(22.7 \%$ and 
$28.9 \%$ ), excursions to various enterprises, organizations (21, 3\% and $26.9 \%) .17 .3 \%$ of respondents in G1 and $21.2 \%$ in G2 stated that no activities were held with them.

Table 1. Socio-demographic characteristics of the respondents.

\begin{tabular}{|c|c|c|c|c|c|c|}
\hline \multirow{2}{*}{ Characteristics } & \multicolumn{2}{|c|}{ Total $(n=127)$} & \multicolumn{2}{|c|}{ G1 $(n=75)$} & \multicolumn{2}{|c|}{ G2 $(n=52)$} \\
\hline & $\mathbf{n}$ & & & $\%$ & & $\%$ \\
\hline $\begin{array}{l}\text { Gender: } \\
\text { female } \\
\text { male }\end{array}$ & $\begin{array}{c}105 \\
22\end{array}$ & $\begin{array}{l}82.7 \% \\
17.3 \% \\
\end{array}$ & $\begin{array}{l}64 \\
11\end{array}$ & $\begin{array}{l}85.3 \% \\
14.7 \%\end{array}$ & $\begin{array}{l}41 \\
11\end{array}$ & $\begin{array}{l}78.8 \% \\
21.2 \%\end{array}$ \\
\hline Age: & & & & & & \\
\hline 17 & 19 & $14.9 \%$ & 12 & $16 \%$ & 7 & $13.5 \%$ \\
\hline 18 & 96 & $75.6 \%$ & 53 & $70.7 \%$ & 43 & $82.7 \%$ \\
\hline 19 & 9 & $7.1 \%$ & 8 & $10.7 \%$ & 1 & $1.9 \%$ \\
\hline 20 и выше & 3 & $2.4 \%$ & 2 & $2.6 \%$ & 1 & $1.9 \%$ \\
\hline Place of residence: & & & & & & \\
\hline City-Regional center & 68 & $53.6 \%$ & 40 & $53.3 \%$ & 28 & $53.9 \%$ \\
\hline City/Village-District center & 45 & $35.4 \%$ & 26 & $34.7 \%$ & 19 & $36.5 \%$ \\
\hline Rural settlement & 14 & $11 \%$ & 9 & $12 \%$ & 5 & $9.6 \%$ \\
\hline Financial situation of the family: & & & & & & \\
\hline Wealthy, can afford a paid training & 14 & $11 \%$ & 8 & $10.7 \%$ & 6 & $11.5 \%$ \\
\hline Average income & 81 & $63.8 \%$ & 48 & $64 \%$ & 33 & $63.5 \%$ \\
\hline The lower-middle-income & 21 & $17.3 \%$ & 13 & $17.3 \%$ & 9 & $17.3 \%$ \\
\hline The low income & 10 & $7.9 \%$ & 6 & $8 \%$ & 4 & $7.8 \%$ \\
\hline Training Program: & & & & & & \\
\hline Teacher training & 97 & $76.4 \%$ & 71 & $94.7 \%$ & 26 & $50 \%$ \\
\hline Sociology and social work & 30 & $23.6 \%$ & 4 & $5.3 \%$ & 26 & $50 \%$ \\
\hline
\end{tabular}

Most of the students also showed an independent interest in the issues of choosing a profession and career development. On this issue, the preferences of the respondents of the two groups differ: the students of G1 more often discussed these issues with their parents and other adults (64\%), less often applied for information about educational programs on the websites of universities $(42.7 \%)$, and twice less often used special training courses, or online information resources (33.3\%). The students of G2 almost all actively used Internet resources $(96.2 \%)$, especially informational and educational $(46.2 \%)$, although they also talked with relatives $(57.7 \%)$. At the same time, $10.7 \%$ (G1) and $15.4 \%$ (G2) of respondents noted that they were not specifically interested in such questions.

$37.3 \%$ of the students of G1 and only $13.5 \%$ of G 2 spoke positively about the certainty with the choice of their future profession. Another $34.7 \%(\mathrm{G} 1)$ and $32.7 \%(\mathrm{G} 2)$ of respondents note the attractiveness of a certain professional sphere but have not yet decided whether they will work in it in the future. Only $28 \%(\mathrm{G} 1)$ versus $53.4 \%(\mathrm{G} 2)$ of students have not yet decided on their professional future. One of such significant factors for a number of students was the COVID-19 pandemic. The students noted a number of difficulties they faced in the transition to distance learning. First of all, this is an increase in the number of homework, which was noted by $56 \%(\mathrm{G} 1)$ and $44.2 \%(\mathrm{G} 2)$ students. $54.7 \%$ (G1) and $40.4 \%(\mathrm{G} 2)$ of respondents drew attention to the lack of explanations of teachers. Another difficulty was the change in the daily routine for $26.7 \%(\mathrm{G} 1)$ and $21.2 \%(\mathrm{G} 2)$ of students. Also, a number of graduates experienced difficulties in exploration various online platforms: this was noted by $25 \%(\mathrm{G} 2)$ and $14.7 \%(\mathrm{G} 1)$. At the same time, students of $\mathrm{G} 2$ easily adapted to new conditions (30.8\%) than students of G1 (24\%). According to respondents from both groups, the transition to remote learning caused by the pandemics did not negatively affect their academic performance; many said that it even improved in general or in certain subjects: this was noted by $44 \%(\mathrm{G} 1)$ and $48.8 \%(\mathrm{G} 2)$ of respondents.

As for preparing for the Unified State Exam as one of the most important tasks of school graduates, opinions were divided on this issue: respondents of G1 more often noted that they were able to allocate more time to prepare for the Unified State Exam in the new conditions (46.7\% vs. 36.6\%). Respondents of G2 more often noted as a problem that 
teachers could not give them enough time (44.2\% vs. $37.3 \%)$, and they also had difficulties in organizing classes with tutors $(32.7 \%$ vs. $16 \%)$. As a result, there are significant differences in the compliance of expectations with the results of the Unified State Exam: a third of students in G1 (33.3\%) and less than a quarter of G2 (23.1\%) received the expected points. However, the discrepancy between the expectations of students in G2 prevails both in the direction of higher results (25\% vs. $18.7 \%$ in G1) and lower (51.9\% vs. $46.7 \%)$.

For our study, it is important to answer the question about the impact of the pandemic on the choice of the place of study (university and training program). The majority of students in G1 (81.3\%) said that their plans have not changed, and they enrolled where they wanted. A similar answer was given by $57.7 \%$ in G2. In the questionnaire, we identified two levels of the impact of the pandemic on changes in the plans of applicants: first, the direct impact, expressed in restrictions on movement between regions and states. This reason was noted by only $8 \%$ of respondents of G1 and $11.5 \%$ of G2. The second level is indirect, as it is explained by lower scores on the Unified State Exam, due to difficulties in learning and training in remote learning, which was indicated by $10.7 \%$ of respondents in G1 and $30.8 \%$ in $\mathrm{G} 2$.

Significant differences in the responses of students of both groups were not found when identifying the attitude to the system of remote admission of documents to universities. More than half of the respondents noted its advantages such as ease of submitting documents to universities in different regions $(50.7 \%(\mathrm{G} 1)$ and $59.6 \%(\mathrm{G} 2))$ and more rapid monitoring of ratings $(53.3 \%$ and $50 \%)$. Among the difficulties of the innovation, technical problems of the work of personal accounts were noted (36\% and $40.4 \%$ ), and $30 \%$ of the respondents of both groups believe that the personal submission of documents allows them to better get acquainted with the university.

Among the students of G1, a larger number study at their own expense (53.3\%). Also, a significant part of the students of this group, studying in government-funded places $(61.5 \%)$, answered in the affirmative to the hypothetical question of whether they were ready to pay for their education independently. The share of students study at their own expense is only $36.5 \%$ in G2. This is another external motive for students of G2 is to study in a government-funded place.

The results of diagnostics of the level of development of personal competencies that are important for career self-determination are presented in Table 2.

Table 2. Comparison of indicators of personal competencies those are important for career selfdetermination.

\begin{tabular}{|c|c|c|c|}
\hline \multirow{2}{*}{ Factor } & \multicolumn{2}{|c|}{ Average value } & \multirow[t]{2}{*}{ t-test } \\
\hline & G1 & G2 & \\
\hline \multicolumn{4}{|c|}{ Primary factors } \\
\hline APS & 7.3 & 6.8 & $2,16664 *$ \\
\hline $\mathrm{AP}$ & 8.1 & 7.7 & 1,82125 \\
\hline SRS & 8.3 & 7.7 & $2,87252 * *$ \\
\hline SSS & 8 & 7.1 & $3,45615 * * *$ \\
\hline $\mathrm{SH}$ & 8.1 & 7.3 & $3,01665 * *$ \\
\hline PS & 7.8 & 7.2 & $2,14455^{*}$ \\
\hline EPPT & 7.7 & 7.1 & $2,44837 * *$ \\
\hline EST & 7.5 & 6.7 & $2,57324 * *$ \\
\hline \multicolumn{4}{|c|}{ Secondary factors } \\
\hline $\mathrm{C} 1$ & 7.8 & 7.2 & $2,734680 * *$ \\
\hline $\mathrm{C} 2$ & 7.6 & 6.9 & $3,222996 * *$ \\
\hline $\mathrm{C} 3$ & 8.3 & 7.8 & $2,721839 * *$ \\
\hline $\mathrm{C} 4$ & 7.8 & 7.2 & $2,144546^{*}$ \\
\hline
\end{tabular}

Note: ${ }^{*}$ - $\leq 0,05 ;{ }^{* *}$ - $\leq \leq 0,01 ;{ }^{* * *}$ - $\mathrm{p} \leq 0,001$. 
As can be seen from the data presented, on average, the respondents of both groups have fairly high results in all factors, but the respondents from G1 have higher indicators, the reliability of the differences of which is statistically confirmed in all competencies except for the AP factor. Also, based on the results of comparing the proportion of students with different levels of development of secondary factors, it can be stated that in all four competencies, the percentage of test subjects in G1 with indicators corresponding to a high level significantly exceeds the proportion of test subjects in G2, who mainly have indicators of an average level (Table 3 ).

Table 3. Comparison of the level of secondary factors (\%).

\begin{tabular}{|c|c|c|c|c|c|c|c|c|}
\hline \multirow{2}{*}{ Level } & \multicolumn{2}{|c|}{ C1 } & \multicolumn{2}{c|}{ C2 } & \multicolumn{2}{c|}{ C3 } & \multicolumn{2}{c|}{ C4 } \\
\cline { 2 - 9 } & G1 & G2 & G1 & G2 & G1 & G2 & G1 & G2 \\
\hline Low & 4.0 & 9.6 & 1.3 & 9.6 & 2.7 & 5.8 & 5.3 & 7.7 \\
\hline Average & 56.0 & 71.2 & 45.3 & 61.5 & 62.7 & 75.0 & 61.3 & 71.2 \\
\hline Tall & 40.0 & 19.2 & 53.3 & 28.9 & 34.7 & 19.2 & 33.3 & 21.2 \\
\hline
\end{tabular}

The results of the correlation analysis generally show the presence of high positive correlations between primary and secondary factors, which indicates a high level of integration and consistency of various components of career development competencies. The main differences between the subjects of the first and second groups are 1) in the students of G1, the EST factor was the only one that showed no relationship with other primary factors; 2) in the students of G2, the factor that scored the least number of correlations was AP: 2 out of 7 (correlations with the APS factors - 0.69 and SSS - 0.62). The obtained data, in our opinion, emphasize that the significant difference between the students of G2 is the lack of knowledge about their own inclinations and abilities, which does not allow them to form conscious professional and career plans.

\section{Conclusions}

According to the results of the study, it is clear that educational organizations and families contribute to the development of professional self-determination of university applicants: there are very few test subjects with a low level of career self-determination competencies. However, the organization of professional orientation at school: training in a specialized class or individual career guidance activities - has less influence on the formation of professional and career plans than parents. At the same time, the role of independent information search and the use of educational resources on the Internet is increasing.

The impact of the pandemic on career self-determination is mediated by the presence of formed professional plans among young people, expressed at this stage in a conscious choice of the place of admission (training program and university) associated with the further sphere of professional activity. Most of these graduates were not prevented by the pandemic from realizing their plans. In contrast, graduates who were undecided about their future were more likely to report that their admission was affected by the restrictions associated with the pandemic. This effect was due to the introduction of remote learning, the complexity of preparing for the Unified State Exam, and, as a result, getting lower academic scores than expected. As the results of diagnostics show, this group of test subjects in the structure of the competencies of career self-determination has a weak connection between the ideas about the features of their own personality and other components, which indicates the underdevelopment of ideas about the professional development of their personality and, consequently, the lack of formation of professional and career plans.

The results of the study allow us to talk about the peculiarities of the career selfdetermination of school graduates who enrolled in a regional university. In our study, these 
are mainly young people living in cities of the regional level or city/village-district centers, whose families have an average income. In our study, the number of young people from rural settlements and low-income families is not representative. We also did not study the career plans of graduates who entered vocational education organizations and joined the army. Perhaps for school graduates from these social and educational groups, the impact of the negative consequences of the pandemic on career self-determination is more significant and requires a separate study.

\section{References}

1. M. L. Savickas, L. Nota, J. Rossier, J.-P. Dauwalder, M. E. Duarte, J. Guichard, S. Soresi, R.Van Esbroeck, A.van Vianen, JVB, 75(3), 239 (2009)

2. V. I. Blinov, E. Y. Esenina, N. F. Rodichev, I. S. Sergeev, Vocational Guidance and Professional Self-Determination of Students: Challenges of Time, 34 (2020)

3. L. Bezanson, CCDF, 4, 1 (2003)

4. E. V. Minina, E. S. Pavlenko, M. A. Kiryushina, A. A. Yakubovskaya, Mod. Analysis of Educ., 2(51) (2021)

5. E. V. Kovalevskaya, Early Career Self-Determination: Structural and Content Characterisation and Formation (2015)

6. F. Kremen, S. Kremen, IFTE-2020, 1277 (2020)

7. O. V. Moskalenko, Acme., 4(44), 24 (2012)

8. I. S. Sergeev, Vocational Guidance and Professional Self-Determination of Students: Challenges of Time, 242 (2020)

9. S. Hansen, CDQ, 47, 353 (1999)

10. D. Perkins, C. Peterson, The role of parents in career transition support (2005)

11. M. Russell, M. Wardman, The value of information types and sources for Year 11 decision making (Department for Education and Employment, Sudbury, Suffolk, 1998)

12. M. O. Quadri, LPP, 3, 7 (2018)

13. I. A. Sakhovsky, Siberian Ped. J., 6, 359 (2010)

14. D. L. Schacter, D. R. Addis, R. L. Buckner, Ann N. Y. Acad. Sci., 1124, 39 (2008).

15. M. C. Ginevra, C. Annovazzi, S. Santilli, I. Di Maggio, E. Camussi, CDQ, 66, 233 (2018)

16. J. Simons, M. Vansteenkiste, W. Lens, M. Lacante, Educ. Psychol. Rev., 16, 121 (2004)

17. Monitoring the economics of education, 1 (133) (2019)

18. W. C. J. Mau, CDQ, 53(1), 57 (2004)

19. L. Bezanson, S. Hopkins, R. A. Neault, CJCP, 50, 219, (2016)

20. J. Bielinski, R. Brown, K. Wagner, COVID Slide: Research on Learning Loss \& Recommendations to Close the Gap (2020) https://f.hubspotusercontent20.net

21. NIU HSE policy brief on the economic and social impact of coronavirus in Russia and globally, 6 (2020)

22. M. A. Kraft, N. S. Simon, Teachers' experiences working from home during the COVID-19 pandemic (2020) https://f.hubspotusercontent20.net 
23. I. V. Abankina, A. A. Vavilova, K. V. Zinkovsky, K. A. Semenova, N. E. Surkova. Mod. Analysis of Educ., 14(44) (2020)

24. M. N. Artemenkov, E. E. Sukhova, Reg. Stud., 2(68), 111 (2020).

25. S. S. Malinovskiy, E. Yu. Shibanova, Regional Differentiation of Access to Higher Education in Russia (2020)

26. V. A. Koksharov, D. G. Sandler, P. D. Kuznetsov, A. V. Klyagin, O. V. Leshukov, Educ. Stud. Mos., 1, 52 (2021)

27. S.-J. Wu, D.-F. Chang, F.-R. Sun, Educ. Sci., 10, 218 (2020)

28. A. Kecojevic, C.H. Basch, M. Sullivan, N.K. Davi, PLoS ONE 15(9), e0239696 (2020) 